\title{
Railway Container Station Reselection Approach and Application: Based on Entropy-Cloud Model
}

\author{
Wencheng Huang, Bin Shuai, Lei Wang, and Eric Antwi \\ School of Transportation and Logistics, Southwest Jiaotong University, Chengdu, Sichuan 610031, China \\ Correspondence should be addressed to Wencheng Huang; hwc2014200864@my.swjtu.edu.cn
}

Received 7 June 2016; Revised 14 November 2016; Accepted 16 November 2016; Published 5 January 2017

Academic Editor: Peide Liu

Copyright (C) 2017 Wencheng Huang et al. This is an open access article distributed under the Creative Commons Attribution License, which permits unrestricted use, distribution, and reproduction in any medium, provided the original work is properly cited.

\begin{abstract}
Reasonable railway container freight stations layout means higher transportation efficiency and less transportation cost. To obtain more objective and accurate reselection results, a new entropy-cloud approach is formulated to solve the problem. The approach comprises three phases: Entropy Method is used to obtain the weight of each subcriterion during Phase 1, then cloud model is designed to form the evaluation cloud for each subcriterion during Phase 2, and finally during Phase 3 we use the weight during Phase 1 to multiply the initial evaluation cloud during Phase 2. MATLAB is applied to determine the evaluation figures and help us to make the final alternative decision. To test our approach, the railway container stations in Wuhan Railway Bureau were selected for our case study. The final evaluation result indicates only Xiangyang Station should be renovated and developed as a Special Transaction Station, five other stations should be kept and developed as Ordinary Stations, and the remaining 16 stations should be closed. Furthermore, the results show that, before the site reselection process, the average distance between two railway container stations was only $74.7 \mathrm{~km}$ but has improved to $182.6 \mathrm{~km}$ after using the approach formulated in this paper.
\end{abstract}

\section{Introduction}

With the rapid development of the global economy, the movement of goods becomes more frequent and container transport becomes an inevitable trend for modern logistics movement especially the railway container transport mode. Railway container transport plays an irreplaceable role in international container logistics and intermodal transport system because it is weatherproof, environmentally friendly, and safe. Also, it has lower tariffs and larger transport capacity as compared with other container transport modes. During the past 60 years, China has made great progress in railway container transport development and modernization. According to their actual function, scale, and container transport volume, the railway container stations can be divided into three categories in China: Center Stations (CS), Special Transaction Stations (STS), and Ordinary Stations (OS). The China Eleventh Five-Year Plan (2006-2010) shows that 18 CS will be planned and constructed in China's main cities; 44 STS and 100 OS will be selected from the 520 existed railway container stations at present for modernization. The threeclass railway container stations will work as the main sites in China's railway container transport network. The layout of the $18 \mathrm{CS}$ and the existing railway container transport network in China is presented in Figure 1.

However, China's railway container transport faces some challenges and competition from other modes of transport. Available data shows that (i) road container transport mode accounts for $77 \%$ of China's total container transport volume; $18 \%$ of containers are transported by waterway and only $5 \%$ by railway. (ii) During the past 5 years, the average annual growth rate of railway container transport volume in China was $11.6 \%$, which is lower than the $23.0 \%$ and $15.6 \%$ annual growth rates for road and waterway transport modes, respectively. (iii) The proportion of railway container transport volume accounts for only $6 \%$ of total railway cargo transport volume in China, far from the world average proportion of $20 \%$ to $40 \%$, with the USA, France, and England figures around $49 \%, 40 \%$, and $30 \%$, respectively. (iv) The proportion of container volume in East China and 


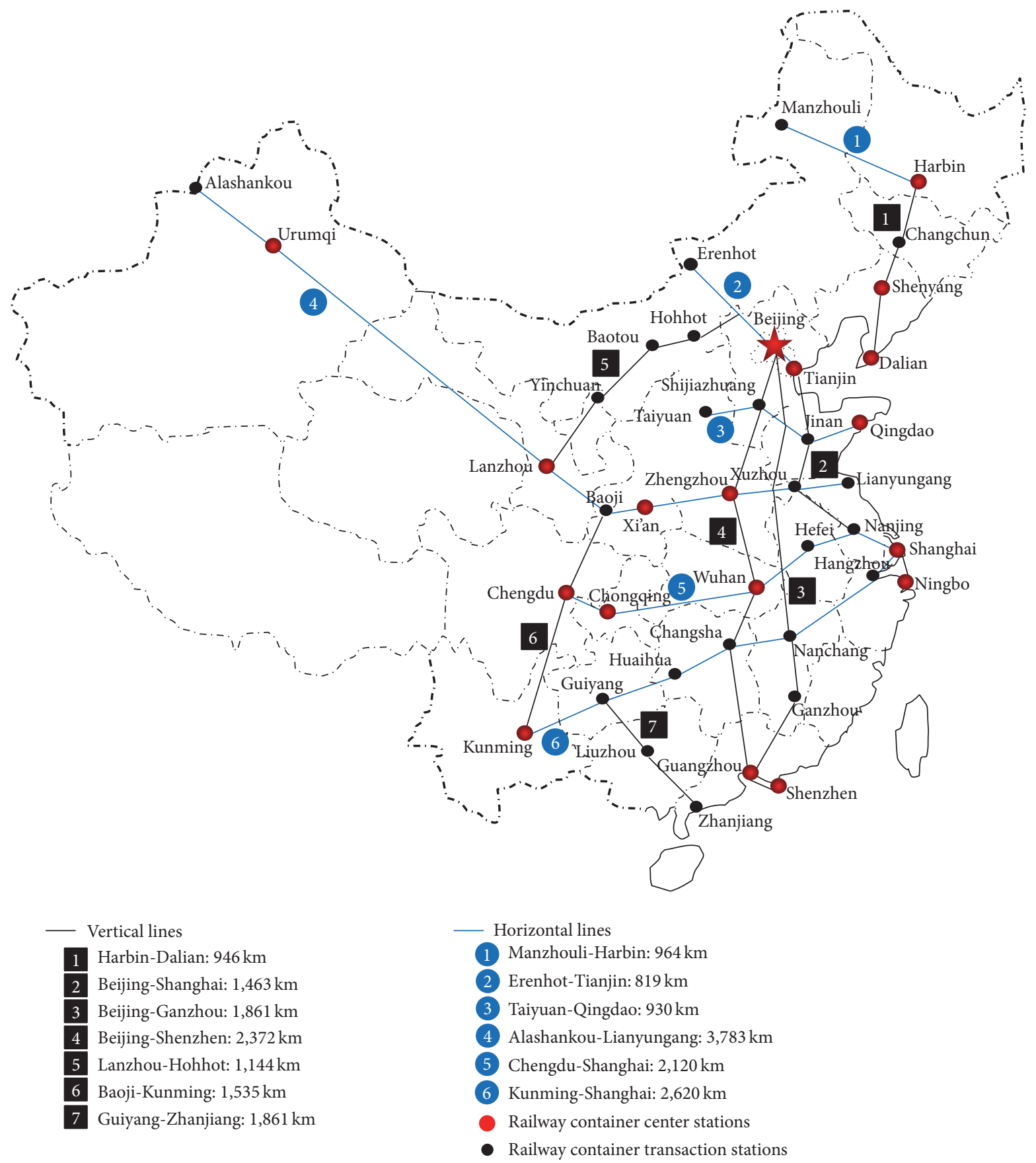

FIGURE 1: Main railway container operation network layout in China.

Southern China accounts for $75 \%$ of the total container cargo while West China is only $4 \%$. The unreasonable railway container transportation site location is a major factor which has contributed to the low railway cargo transport volume and unbalanced container transport modes in China. There are 520 railway container stations in China's railway network now but the transport capacity is weak, the layout of the stations remains unbalanced, and the average distance is relatively short between any two stations and does not offer any economies of scale with its potential. The average effective influence radiation radius is nearly 107 kilometers. In some developed countries, the data is over 480 kilometers according Wang [1]; please see Table 1 to compare the difference between China and some foreign countries.

To maximize the effectiveness and competitiveness of railway container transport, it is essential to reselect the railway container stations. The railway container stations selection process should be undertaken with a strategic view, due 
TABLE 1: Basic data comparison between China and some foreign countries.

\begin{tabular}{lccccc}
\hline & America & Canada & Russia & India & China \\
\hline NRCS & 161 & 42 & 173 & 40 & 520 \\
TROL $(\mathrm{km})$ & 260,000 & 46,552 & 87,157 & 64,015 & 120,000 \\
ASL $(\mathrm{km})$ & 1,615 & 1,108 & 504 & 1600 & 231 \\
\hline
\end{tabular}

NRCS: the number of railway container stations. TROL: the total railway operation length. ASL: the average service length for each railway container station.

to its long construction period, huge economic investment, and nearly no huge returns in the short term. When we select and plan the sites, the railway container transport demand and development pattern must be considered carefully. The railway container station selection process aims to determine the sites number and their location. A reasonable railway container station layout has a direct impact on the whole logistics system. A high efficient operational logistics system means lower costs, higher efficiency, and higher level of service.

In this paper, we aim to evaluate and select the railway container station based on the existing stations layout in China which as described above can be classified as sites selection problem (SSP). We will find the optimum sites that meet the predetermined selection factors and formulate an entropy-cloud approach to solve the SSP. The method combines Entropy Method (EM) and cloud model (CM). The remainder of this paper is organized as follows. In Section 2 we give a brief literature review about SSP, EM, and CM, and in Section 3 we introduce the detail railway container station evaluation indexes used to reselect the sites. Then an EntropyCloud Model (ECM) is formulated to reselect the railway container stations in Section 4. Next, Section 5 is devoted to the description and evaluation of the numerical experiments. Finally, Section 6 presents the major conclusions and gives an outline of future research tasks.

\section{Previous Research}

2.1. Literature Review on SSP Approaches. Nowadays, a lot of research works and papers have already been devoted to sites selection problems. The most commonly used method to solve the SSP is Analytic Hierarchy Process (AHP). AHP transforms a flexible multicriteria decision-making problem into a hierarchy with respect to one or more criteria and it has been widely used for a variety of sites selection problems. For example, Ballis [2] used AHP to select the airport-site location on the Island of Samothraki, Greece. The method has also been used for transshipment site selection (Önüt and Soner [3]); transit site selection (Rosenberg and Esnard [4]); weapon selection problem (Dağdeviren et al. [5]); industrial site selection (Kauko [6], Kauko [7], Srdjevic et al. [8], Dey and Ramcharan [9]); location for warehouses and suppliers (Liu et al. [10], García et al. [11]); location of solid waste plant (Padmaja et al. [12]); location of petroleum pipelines (Dey [13]); location of animal waste plant (Timor and Sipahi [14]). Except those that have been used individually to select sites above, Korpela et al. [15] used an approach which combined AHP and Data Envelopment Analysis (DEA) to select a warehouse operator network. Also, Akinci et al. [16] used AHP and Geographic Information System (GIS) to select suitable lands for agriculture. The same approach was also used for the location of photovoltaic power plants (Carrión et al. [17]) and location of solid waste plant (Kontos et al. [18]). Furthermore, Cheng et al. [19], Banar et al. [20] and Aragonés-Beltrán et al. [21] combined AHP and Analytic Network Process (ANP) to select solid waste plant location. Ekmekçioĝlu et al. [22] and Önüt et al. [23] used a method combining AHP and Technique for Order of Preference by Similarity to Ideal Solution (TOPSIS) to solve the location of solid waste plant problem and industrial site selection problem, respectively. AHP works as the following four steps: (i) establish hierarchy model for an exact SSP, (ii) form a judgment matrix, (iii) calculate the relative weights for each element under a single criterion, and (iv) calculate the comprehensive weight. Generally, we use Expert Scoring Method (ESM) to obtain the evaluation weights; the results are quite subjective and inaccurate.

Except for the AHP, some other techniques and approaches have also been devoted to the SSP. Hoffman and Schniederjans [24] applied expanding the classification or scoring methods to select a global facility site. Brimberg and ReVelle [25], Schmidt, and Wilhelm [26] used Linear Programming (LP) to choose facility location and multinational logistics networks design, respectively. Furthermore, Rönnqvist et al. [27] applied Heuristic approach to solve the single-source capacitated facility location problem. Similarly, the multicriteria mapping was also used especially the TOPSIS for facility site selection (Liang and Wang [28]) and gas station site selection (Semih and Seyhan [29]). Felice et al. [30] provided ANP to evaluate influence of green practices on supply chain performance; the ANP works as the following five steps: (i) pairwise comparison and relative weight estimation, (ii) consistency index estimation, (iii) formation of the initial super matrix, (iv) formation of weighted super matrix, and (v) Calculation of global priority vectors and weights.

All the summarized approaches, methods, and techniques above require experience and knowledge from the evaluators and experts; sometimes the calculation results are subjective and inaccurate. Since a few years ago artificial intelligence and expert systems have been used in the SSP for searching the appropriate solutions such as GIS. There are three steps involved for a SSP approach: (i) create vulnerability map with various factors, (ii) create P map and I map to apply the equation of Pts map, and (iii) GIS software locates the best sites. Mahamid and Thawaba [31] used GIS to solve landfill site selection problem in Palestine. Also, Mendas 
and Delali [32] applied GIS to develop land suitability maps for agriculture. In the same way, Decision Support Systems (DSS) were also being applied to SSP, which is supported by the Online Analytical Processing (OLAP) System and Data Mining (DM) System. For example, Uyan et al. [33] combined DSS and GIS to help land reallocation.

2.2. Literature Review on EM and CM. Cloud theory was first delimited and applied by Li et al. [34]. CM can synthetically describe the randomness and fuzziness of qualitative information and implement uncertain transformations between qualitative information and its quantitative instantiations based on probability statistics and fuzzy set theory. Usually the CM uses the forward cloud transformation (FCT) and the backward cloud transformation (BCT) to implement the cognitive transformations, which can reduce greatly loss of information. Now it has been used extensively in many fields like natural language processing, data mining, decision analysis, intelligent control, image processing, and so on. Li et al. [35] used CM to evaluate the smart distribution grid; the evaluation model included two parts: synthesized cloud and remarks cloud. The final evaluation results were given in the form of probability distribution. Also, Fan et al. [36] applied the improved evaluation method based on $\mathrm{CM}$ for situation consistency within the battlefield of joint operations. The improved assessment approach was based on Cloud Gravity Centre Theory and used Structure Entropy Weight to calculate the weight of the indexes. Furthermore, the CM was also used for risk management; for example, Zhang et al. [37], Li et al. [38], and Zhang et al. [39], and route assessment; see $\mathrm{Ma}$ and $\mathrm{Xu}$ [40]. Wu et al. [41] proposed a cloud-based decision framework to solve the waste-to-energy plant site selection problem (SSP). Deng et al. [42] combined Heuristic Gaussian cloud transformation and fuzzy forecasting method to solve the novel hybrid water quality time series prediction problem. Wu et al. [43] proposed prioritized aggregation operators and cross-entropy measures to solve the multicriteria decision-making problems based on the simplified neutrosophic numbers. Wang et al. [44] proposed a likelihood-based TODIM approach based on multihesitant fuzzy linguistic information, which was used to solve multicriteria decision-making problems under bounded rationality, and hesitance and repetitiveness information in logistics outsourcing. Zhang et al. [45] built a multicriteria group decision-making approach to singlevalue neutrosophic environments. The approach is combined with a neutrosophic normal cloud (NNC) and several other related concepts, including a backward cloud generator, two aggregated operators, and an NNC distance measurement. Zhang et al. [46] proposed a fuzzy multicriteria decisionmaking approach based on cloud model and prospect theory in e-commerce. Liu and Shi [47] proposed the decisionmaking method for multiple attribute group decision-making with interval neutrosophic hesitant fuzzy information and gave the detailed decision steps. Liu et al. [48] proposed a new method based on the generalized hybrid operators in order to solve the multiple attribute decision-making problems in which the attribute values take the form of the 2-dimension uncertain linguistic information.
Some recent papers have also been devoted to the development of CM theoretical research. Wang et al. [49] proposed a linguistic multicriteria group decision-making method based on three kinds of cloud aggregation operators, including cloud weighted arithmetic averaging operator, cloudordered weighted arithmetic averaging operator, and cloud hybrid arithmetic operator. Also, Wang et al. [50] used CM to solve the uncertain linguistic multicriteria group decisionmaking problem. Wang et al. [51] established a generic normal cloud model and then designed and compared some algorithms to solve the model which included 2nd2ndorder generic normal cloud model (2nd2nd-GFCT), 2nd2ndorder generic forward normal cloud transformation algorithm (2nd2nd-GIBCT), 2nd2nd-order generic backward cloud transformation algorithm (2nd2nd-GBCT), pthpthorder generic forward normal cloud transformation algorithm (pthpth-GFCT), and the backward cloud transformation algorithm (pthpth-GBCT). Fruit Fly Optimization Algorithm (FOA) is a new global optimization algorithm inspired by the foraging behavior of fruit fly swarm. To improve the convergence performance of FOA, Wu et al. [52] proposed a new model which combined the normal CM and FOA to solve the problem. Li et al. [53] proposed a new carbon performance evaluation system for energy utilization by Fuzzy AHP and CM. The former is used to accumulate the indicator weights and the latter is incorporated when the indicator value is fuzzy.

EM always works as a basic approach to calculate the weight when we evaluate some systems, networks, and so forth. The smaller the index Entropy Value, the greater the amount of information provided by this index and the higher the weight after the comprehensive evaluation process. In this paper, we tried to formulate an evaluation approach by combining EM and CM, called Entropy-Cloud Model (ECM), to solve the railway container station reselection problem. We used EM to calculate the index weight during the SSP evaluation process; then the CM was applied to realize uncertain mapping between evaluation reviews and index values. During the whole sites selection process the evaluation randomness was maintained.

\section{The Related Evaluation Indexes}

This paper aims to evaluate the railway container station with three alternatives: renovate and develop the present station as a STS or as an OS, or the railway container station should be closed down. Figure 2 shows the detailed levels and structure about our evaluation model. Each station will be evaluated as shown in the second level. The goal of the model is divided into five main criteria including transport volume, equipment, location layout, rail-related, and economic. The third level consists of 18 subcriteria which are related to the main criteria. All the criteria and subcriteria are determined by 10 experts, including 5 Professors and 1 Associate Professor in School of Transportation and Logistics, Southwest Jiaotong University. And 4 Senior Engineers in China Railway Siyuan Survey and Design Group CO., LTD. All experts' specialization is railway operation network planning and design. The following list shows the detailed subcriteria information. 


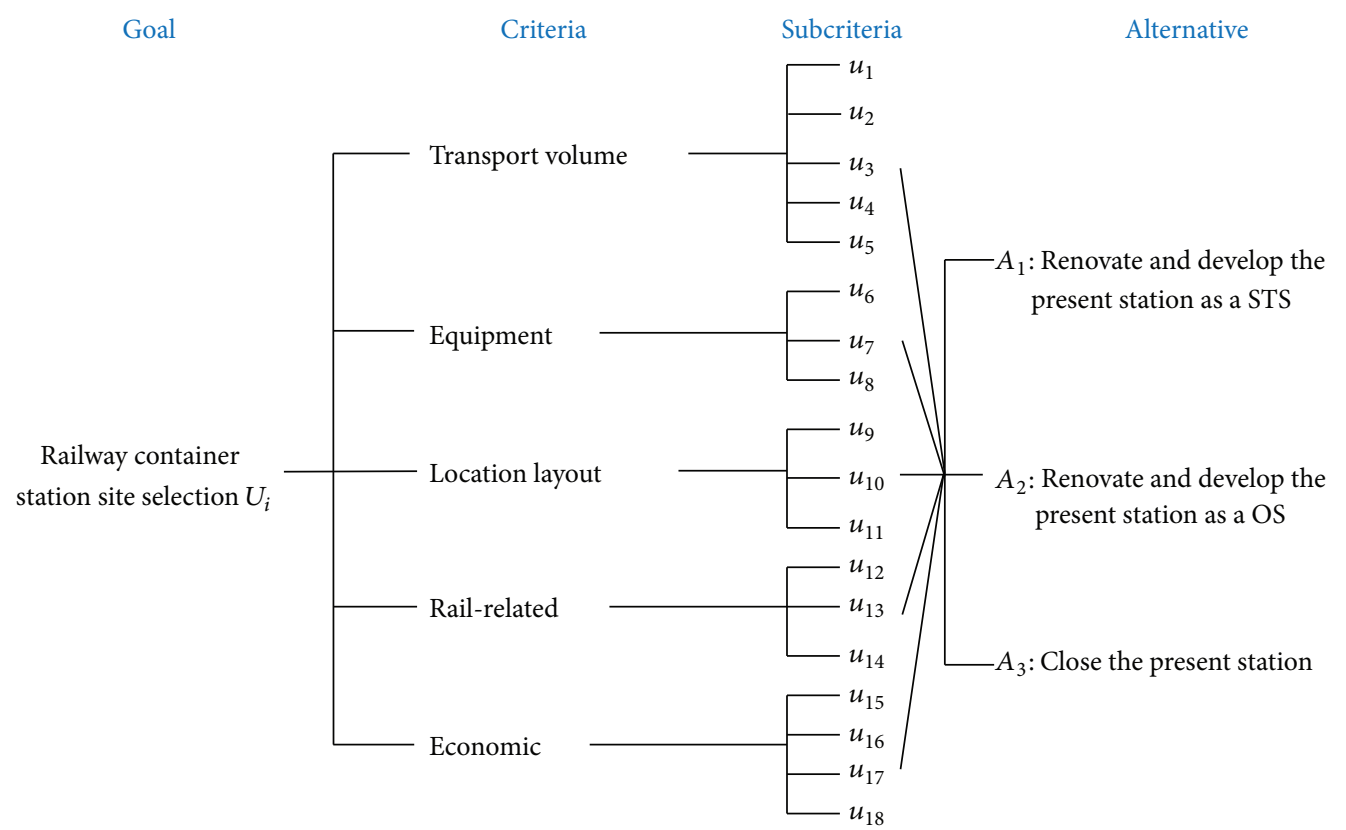

FIGURE 2: Evaluation indexes framework for each station.

Detailed Information about the Subcriteria

Transport Volume

Current container throughput volume $u_{1}$.

Throughput volume 5 years later $u_{2}$.

Volume change trend during the 5 years $u_{3}$.

Arrival and departure track volume $u_{4}$.

Seasonal goods proportion $u_{5}$.

\section{Equipment}

Equipment condition and ability $u_{6}$.

Equipment remaining ability $u_{7}$.

Renovation and expansion possibility $u_{8}$.

\section{Location Layout}

Goods sources intensity $u_{9}$.

Network reachability $u_{10}$.

Average line length among stations $u_{11}$.

\section{Rail-Related}

Integrated transport capacity $u_{12}$

Road network density $u_{13}$.

Convenience of transferring $u_{14}$.
Economic

Area properties $u_{15}$.

Regional economic level $u_{16}$.

Economic development prospects $u_{17}$

Residents structure around the station $u_{18}$.

\section{ECM Evaluation Process Formulation}

To significantly reduce loss of information when we evaluate the railway container station, the ECM will be proposed to select the STS and the OS. The remaining railway container stations will be closed. The ESM is the basis during ordinary $\mathrm{CM}$ evaluation process, so we try to use EM to obtain the final calculation weight instead of ESM to reduce the subjective and inaccurate factors. The ECM to the SSP will be working as the following three phases.

Phase 1 (evaluation weight based on EM).

Step 1. For each station $i, i=1,2, \ldots, n, n \in N^{+}$, and each subcriteria $u_{j}, j=1,2, \ldots, m, m \in N^{+}$, mentioned in "Detailed Information about the Subcriteria," establish the basic interpretation matrix $R$. For each station and each subcriterion, $r_{i, u_{j}}$ is the initial evaluation data needed to be collected.

$$
R=\left(r_{i, u_{j}}\right)_{n * m}
$$


Step 2. Indicators normalization process for each subcriterion $u_{j} \cdot b_{i, u_{j}}$ is the evaluation value after normalization.

$$
\begin{aligned}
& b_{i, u_{j}}=\frac{\left[\left(r_{i, u_{j}}\right)_{\max }-r_{i, u_{j}}\right]}{\left[\left(r_{i, u_{j}}\right)_{\max }-\left(r_{i, u_{j}}\right)_{\min }\right]}, \\
& \forall u_{j}, j=1,2, \ldots, m, m \in N^{+} .
\end{aligned}
$$

Step 3. For each station $i, i=1,2, \ldots, n, n \in N^{+} . H_{u_{j}}$ is the information entropy for each subcriterion $u_{j}$ and $f_{i, u_{j}}$ is the probability for each subcriterion $u_{j}$.

$$
\begin{aligned}
& H_{u_{j}}=\frac{-\left(\sum_{i=1}^{n} f_{i, u_{j}} \ln f_{i, u_{j}}\right)}{\ln n}, \\
& \forall u_{j}, j=1,2, \ldots, m, m \in N^{+}, \\
& f_{i, u_{j}}=\frac{b_{i, u_{j}}}{\sum_{i=1}^{n} b_{i, u_{j}}}, \quad \forall u_{j}, j=1,2, \ldots, m, m \in N^{+} . \\
& \text {If } f_{i, u_{j}}=0, \text { then we let } f_{i, u_{j}} \ln f_{i, u_{j}}=0 .
\end{aligned}
$$

Step 4. For each subcriterion $u_{j}$, calculate the weight $\omega_{u_{j}}$.

$$
\omega_{u_{j}}=\frac{\left(1-H_{u_{j}}\right)}{\left(m-\sum_{j=1}^{m} H_{u_{j}}\right)}, \quad \forall i, i \in N^{+}
$$

From the above entropy calculation process we can deduce some basic conclusions. If the resulting Entropy Value is smaller, the weight is bigger and very important which means greater amount of information can be gotten from the corresponding assessment indicators. Conversely, the bigger the entropy, the smaller the entropy weight which means the indicators are few and not significant. So, the EM is helpful to get the weight of the indicators objectively.

Phase 2 (form the evaluation cloud for each station based on CM). According to the previous research results, for example, Wang et al. [49], the digital signature of clouds reflects the quantitative characteristics about the qualitative concept. For each station $i, i=1,2, \ldots, n, n \in N^{+}$, and each subcriterion $u_{j}, j=1,2, \ldots, m, m \in N^{+}$, we use three kinds of data to formulate a cloud including Expectation Value $E_{x}^{i, u_{j}}$, Entropy Value $E_{n}^{i, u_{j}}$, and Super Entropy Value $H_{e}^{i, u_{j}}$. We use $G$ as the quantitative characteristics with exact value; $T^{i, u_{j}}$ is the qualitative concept; then

$$
T^{i, u_{j}}=G\left(E_{x}^{i, u_{j}}, E_{n}^{i, u_{j}}, H_{e}^{i, u_{j}}\right), \quad \forall i, u_{j}
$$

So, the evaluation process for each station based on CM is working as follows.

Step 1. ESM to obtain the basic evaluation criteria cloud.
All the railway container stations have three handling alternatives: renovate and develop the present station as a STS or as an OS, or the railway container station would be closed (C). Each kind of alternative is formulated by a basic visualization evaluation cloud. We use ESM together with MATLAB to control the convergence speed and quality of expertise. The final visualization evaluation clouds must meet the overall national strategic planning goal such as the number limitation for each kind of station. The three basic evaluation clouds $T^{\mathrm{STS}}, T^{\mathrm{OS}}$, and, $T^{\mathrm{C}}$ will be used as criteria during the final evaluation process. Please refer to formulas (7) and (8) to get the core calculation steps.

$$
\begin{aligned}
T^{\mathrm{STS}} & =G\left(E_{x}^{\mathrm{STS}}, E_{n}^{\mathrm{STS}}, H_{e}^{\mathrm{STS}}\right), \\
T^{\mathrm{OS}} & =G\left(E_{x}^{\mathrm{OS}}, E_{n}^{\mathrm{OS}}, H_{e}^{\mathrm{OS}}\right), \\
T^{\mathrm{C}} & =G\left(E_{x}^{\mathrm{C}}, E_{n}^{\mathrm{C}}, H_{e}^{\mathrm{C}}\right) .
\end{aligned}
$$

Step 2. For each station $i$ and each subcriterion $u_{j}$, use ESM to obtain the basic subcriteria evaluation value $X_{k}^{i, u_{j}}$. Firstly, calculate the sample mean $E_{x}^{i, u_{j}}$ and sample variance $\left(S_{i, u_{j}}\right)^{2}$, respectively.

$$
\begin{aligned}
& E_{x}^{i, u_{j}}=\frac{1}{N} \sum_{k=1}^{N} X_{k}^{i, u_{j}}, \\
& \forall i, u_{j}, k=1,2, \ldots, N, N \in N^{+} \\
&\left(S_{i, u_{j}}\right)^{2}=\frac{1}{N-1} \sum_{k=1}^{N}\left(X_{k}^{i, u_{j}}-E_{x}^{i, u_{j}}\right)^{2}, \\
& \forall i, u_{j}, k=1,2, \ldots, N, N \in N^{+},
\end{aligned}
$$

where $N$ is the total expert number. We then can obtain the Entropy Value $E_{n}^{i, u_{j}}$ and Super Entropy Value $H_{e}^{i, u_{j}}$ based on the sample mean and sample variance.

$$
\begin{aligned}
& E_{n}^{i, u_{j}}=\sqrt{\frac{\pi}{2}} \frac{1}{N} \sum_{k=1}^{N}\left|X_{k}^{i, u_{j}}-E_{x}^{i, u_{j}}\right|, \\
& \forall i, u_{j}, \quad k=1,2, \ldots, N, N \in N^{+}, \\
& H_{e}^{i, u_{j}}=\sqrt{\left(S_{i, u_{j}}\right)^{2}-\left(E_{n}^{i, u_{j}}\right)^{2}}, \quad \forall i, u_{j} .
\end{aligned}
$$

Phase 3 (obtain the final evaluation results).

Step 1. For each railway container station $i$ under evaluation, to obtain the final evaluation cloud $C_{i}$, we use the weight $\Phi_{u_{j}}$ to multiply the initial evaluation cloud $T^{i, u_{j}}$.

$$
\begin{aligned}
& C_{i}=\sum_{j=1}^{m}{\omega_{u}}_{j} T^{i, u_{j}}, \quad \forall i, \\
& C_{i}=G\left(E_{x}^{i}, E_{n}^{i}, H_{e}^{i}\right), \quad \forall i .
\end{aligned}
$$


Combining formulas (5) and (9), we can obtain the following three formulas used to calculate the $C_{i}$ :

$$
\begin{aligned}
& E_{x}^{i}=\sum_{j=1}^{m} \varrho_{u_{j}} E_{x}^{i, u_{j}}, \quad \forall i, \\
& E_{n}^{i}=\sum_{j=1}^{m}{\omega_{u_{j}}}_{E_{n}^{i, u_{j}},} \quad \forall i, \\
& H_{e}^{i}=\sum_{j=1}^{m} \varrho_{u_{j}} H_{e}^{i, u_{j}}, \quad \forall i .
\end{aligned}
$$

Step 2. Use MATLAB to obtain the visible $C_{i}, T^{\mathrm{STS}}, T^{\mathrm{OS}}$, and $T^{\mathrm{C}}$ in the same interface and compare the four figures; the evaluated station $i$ belongs to one of the alternative $\left(T^{S T S}, T^{\mathrm{OS}}\right.$, or $T^{\mathrm{C}}$ ) if $C_{i}$ is more close to one of the figures. And we can also use the following evaluation method to obtain the final result, adjunctively.

$$
C_{i}=\min \left\{\left|E_{x}^{\mathrm{STS}}-E_{x}^{i}\right|,\left|E_{x}^{\mathrm{OS}}-E_{x}^{i}\right|,\left|E_{x}^{\mathrm{C}}-E_{x}^{i}\right|\right\}, \quad \forall i .
$$

\section{Case Study and Results Discussion}

We now present the numerical experiment of the above railway container station reselection approach. There are 520 railway stations which have container handling services in China but only 44 STS and 100 OS can be retained; the remaining 376 stations must be closed. The railway container stations in Wuhan Railway Bureau were selected for this case study. 22 stations are operating in Wuhan Railway Bureau now and only 6 stations will be retained, so the strategic decision-making from the managers becomes vital.

The three basic evaluation criteria clouds $T^{\mathrm{STS}}, T^{\mathrm{OS}}$, and $T^{\mathrm{C}}$ from the experts and MATLAB as well as the layout of studied railway container transport network in Wuhan Railway Bureau will be introduced as initial data. The other initial data such as the collected $r_{i, u_{j}}$ in Phase 1, the basic expert scoring value $X_{k}^{i, u_{j}}$ for each station $i$, and each subcriterion $u_{j}$ in Phase 2 will not be presented in this paper because of their large scale and limitation of the paper length. The weight for each subcriterion $u_{j}$ in Phase 1 together with the final evaluation cloud $C_{i}$ for each station $i$ in Phase 3 will be presented as the calculation results. As for the evaluation cloud $T^{i, u_{j}}$ in Phase 2, only the data (result) of the 6 retained stations will be presented in this paper because the data scale is large. Furthermore, the final evaluation results will be discussed.

Next we will give some parts of the initial data and calculation results based on AHP. Again, some processes will not be presented in this paper because of their large scale and limitation of the paper length. Finally, the calculation comparison between the ECM and AHP will be presented.

5.1. Initial Data and Calculation Results Based on ECM. To satisfy the basic national strategic planning and station number limitation, we invited 10 experts (including 5 Professors

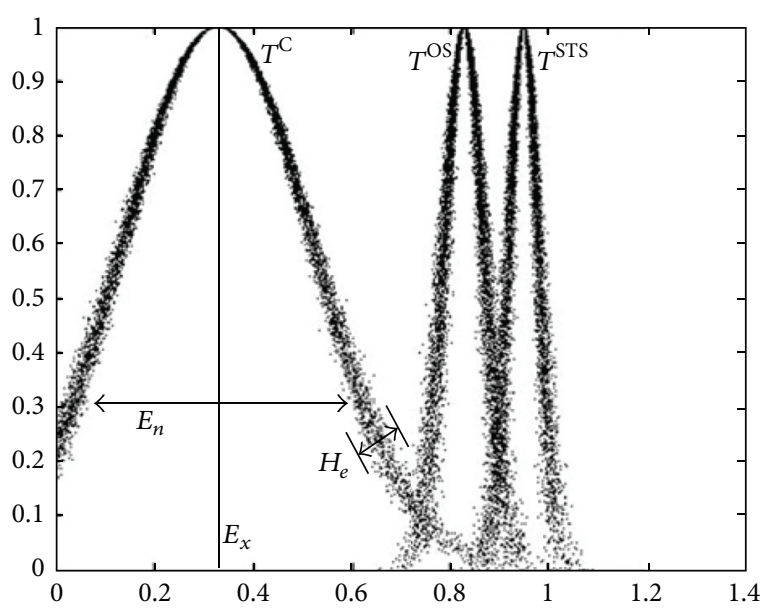

FIgURE 3: Evaluation criteria clouds $T^{\mathrm{STS}}, T^{\mathrm{OS}}$, and $T^{\mathrm{C}}$.

and 1 Associate Professor from School of Transportation and Logistics, Southwest Jiaotong University and 4 Senior Engineers from China Railway Siyuan Survey and Design Group CO. LTD; all experts' specialization is railway operation network planning and design) to evaluate and score for the three kinds of criteria. After transferring the scoring value into evaluation values $E_{x}, E_{n}$, and $H_{e}$, we used MATLAB to make the clouds visual. Some adjustment approaches have also been applied to control the convergence speed and quality of expertise. As a result, the final evaluation clouds criteria are as follows: $T^{\mathrm{STS}}=G(0.95,0.03,0.006), T^{\mathrm{OS}}=$ $G(0.83,0.04,0.007)$, and $T^{\mathrm{C}}=G(0.33,0.19,0.008)$. The final standard clouds are shown in Figure 3, which is the output of the 10 experts' evaluation and scoring.

Other initial data such as current container throughput volume, arrival, and departure track volume were collected from the Railway Customer Service Center of China (www.12306.com), official website of Wuhan Railway Bureau, official website of China Railway Container Transport Co., Ltd. (CRCT), and so forth. The 22 railway container stations in Wuhan Railway Bureau belong to ordinary railway stations with uneven daily container handling amount. We collected the basic location information for each station in the railway network as well as the operation distance between two stations, which will be used as a compared reference when we discuss the final results after railway container site reselection process.

After the calculation process during Phase 1, we can obtain 18 weights for the 18 subcriteria, respectively. The result of the calculation shows that the indicator "throughput volume 5 years later" is the most valuable decision-making factor. Next are current container throughput volume, equipment condition and ability, regional economic level, and so forth. The weights with higher values are all about container transport number, equipment, and economic, which means the three important factors have smaller Entropy Value but with greater amount of information in the corresponding assessment indicators. The detailed results are presented in Table 2. 
TABLE 2: Weight for each subcriterion.

\begin{tabular}{|c|c|c|c|c|c|c|c|c|c|}
\hline$\omega_{u_{j}}, u_{j}=1, \ldots, 9$ & 0.0984 & 0.1064 & 0.0524 & 0.0147 & 0.0125 & 0.0788 & 0.0561 & 0.0472 & 0.0584 \\
\hline$u_{j}=10, \ldots, 18$ & 0.0532 & 0.0298 & 0.0558 & 0.0423 & 0.0421 & 0.0501 & 0.0787 & 0.0607 & 0.0624 \\
\hline
\end{tabular}

TABLE 3: Evaluation cloud for the 6 remaining stations on each subcriterion.

\begin{tabular}{|c|c|c|c|c|c|c|}
\hline \multirow[t]{2}{*}{ Station name } & \multicolumn{6}{|c|}{ Evaluation cloud for each subcriterion } \\
\hline & $(0.94,0.014,0.003)$ & $(0.99,0.019,0.004)$ & $(0.85,0.019,0.001)$ & $(0.82,0.017,0.006)$ & $(0.69,0.012,0.006)$ & $(0.98,0.013,0.001)$ \\
\hline \multirow[t]{3}{*}{ Xiangyang } & $(0.92,0.013,0.002)$ & $(0.89,0.017,0.003)$ & $(0.93,0.011,0.006)$ & $(0.91,0.016,0.005)$ & $(0.87,0.014,0.007)$ & $(0.95,0.012,0.001)$ \\
\hline & $(0.92,0.017,0.001)$ & $(0.95,0.019,0.003)$ & $(0.89,0.015,0.005)$ & $(0.99,0.015,0.004)$ & $(0.98,0.016,0.001)$ & $(0.86,0.011,0.002)$ \\
\hline & $(0.89,0.024,0.004)$ & $(0.87,0.026,0.007)$ & $(0.86,0.029,0.008)$ & $(0.56,0.033,0.007)$ & $(0.84,0.035,0.007)$ & $(0.85,0.034,0.009)$ \\
\hline \multirow[t]{3}{*}{ Zhumadian } & $(0.86,0.025,0.008)$ & $(0.83,0.019,0.009)$ & $(0.86,0.028,0.006)$ & $(0.75,0.027,0.001)$ & $(0.64,0.031,0.004)$ & $(0.66,0.036,0.002)$ \\
\hline & $(0.63,0.031,0.003)$ & $(0.78,0.029,0.005)$ & $(0.56,0.024,0.007)$ & $(0.76,0.026,0.002)$ & $(0.75,0.029,0.003)$ & $(0.37,0.031,0.001)$ \\
\hline & $(0.71,0.021,0.009)$ & $(0.72,0.023,0.008)$ & $(0.70,0.016,0.008)$ & $(0.65,0.020,0.008)$ & $(0.69,0.019,0.007)$ & $(0.72,0.031,0.005)$ \\
\hline \multirow[t]{3}{*}{ Jingmen } & $(0.89,0.023,0.005)$ & $(0.91,0.021,0.006)$ & $(0.55,0.023,0.006)$ & $(0.69,0.023,0.007)$ & $(0.42,0.019,0.009)$ & $(0.52,0.018,0.005)$ \\
\hline & $(0.63,0.012,0.005)$ & $(0.62,0.011,0.009)$ & $(0.89,0.010,0.006)$ & $(0.91,0.016,0.008)$ & $(0.53,0.012,0.008)$ & $(0.44,0.014,0.006)$ \\
\hline & $(0.89,0.035,0.009)$ & $(0.97,0.042,0.008)$ & $(0.91,0.041,0.006)$ & $(0.85,0.039,0.007)$ & $(0.69,0.041,0.008)$ & $(0.88,0.042,0.007)$ \\
\hline \multirow[t]{3}{*}{ Enshi } & $(0.87,0.026,0.009)$ & $(0.99,0.038,0.006)$ & $(0.91,0.036,0.005)$ & $(0.82,0.041,0.006)$ & $(0.83,0.035,0.007)$ & $(0.85,0.039,0.007)$ \\
\hline & $(0.89,0.041,0.008)$ & $(0.91,0.031,0.008)$ & $(0.97,0.044,0.006)$ & $(0.91,0.040,0.006)$ & $(0.96,0.039,0.008)$ & $(0.52,0.033,0.005)$ \\
\hline & $(0.68,0.049,0.008)$ & $(0.89,0.068,0.007)$ & $(0.84,0.056,0.005)$ & $(0.52,0.049,0.009)$ & $(0.56,0.052,0.004)$ & $(0.47,0.036,0.005)$ \\
\hline \multirow[t]{3}{*}{ Xianning } & $(0.55,0.064,0.006)$ & $(0.58,0.035,0.005)$ & $(0.36,0.039,0.007)$ & $(0.34,0.056,0.005)$ & $(0.48,0.069,0.007)$ & $(0.49,0.041,0.006)$ \\
\hline & $(0.44,0.049,0.007)$ & $(0.56,0.057,0.006)$ & $(0.76,0.069,0.005)$ & $(0.64,0.048,0.007)$ & $(0.57,0.056,0.005)$ & $(0.45,0.030,0.005)$ \\
\hline & $(0.77,0.044,0.008)$ & $(0.74,0.056,0.007)$ & $(0.63,0.052,0.007)$ & $(0.65,0.049,0.006)$ & $(0.51,0.051,0.006)$ & $(0.52,0.050,0.006)$ \\
\hline \multirow{2}{*}{ Huangshi East } & $\mathrm{t}(0.69,0.055,0.008)$ & $(0.81,0.046,0.006)$ & $(0.49,0.044,0.005)$ & $(0.56,0.039,0.006)$ & $(0.55,0.033,0.008)$ & $(0.70,0.038,0.006)$ \\
\hline & $(0.77,0.046,0.007)$ & $(0.76,0.055,0.007)$ & $(0.76,0.051,0.007)$ & $(0.75,0.056,0.008)$ & $(0.74,0.047,0.007)$ & $(0.67,0.026,0.007)$ \\
\hline
\end{tabular}

TABLE 4: Final evaluation cloud for each station.

\begin{tabular}{lccc}
\hline \multicolumn{3}{c}{ Abbreviation of railway container station name (final evaluation cloud) } & Alternative \\
\hline XAY $(0.93,0.015,0.003)$ & & & STS \\
\hline ZMD $(0.76,0.028,0.005)$ & JM $(0.69,0.019,0.007)$ & ES $(0.88,0.038,0.007)$ & XN $(0.59,0.051,0.006)$ \\
HSE $(0.68,0.047,0.007)$ & & & \\
\hline MM $(0.42,0.046,0.003)$ & YM $(0.23,0.090,0.004)$ & LH $(0.48,0.041,0.008)$ & XY $(0.55,0.175,0.006)$ \\
SY $(0.51,0.147,0.005)$ & BL $(0.49,0.173,0.009)$ & HSJ $(0.27,0.091,0.004)$ & GC $(0.37,0.140,0.007)$ \\
ZY $(0.39,0.055,0.006)$ & SYD $(0.44,0.101,0.006)$ & LS $(0.12,0.094,0.007)$ & YCE $(0.36,0.174,0.005)$ \\
XYD $(0.25,0.056,0.005)$ & YM $(0.57,0.049,0.007)$ & WJS $(0.28,0.054,0.006)$ & MC $(0.50,0.097,0.004)$
\end{tabular}

STS: Special Transaction Station, OS: Ordinary Station, and C: the railway container station would be canceled. XAY: the abbreviation of railway container station name, Xiangyang, the other station full name can be found in Figure 4.

The experts scored every subcriteria for each station that need to be evaluated according to the final evaluation clouds criteria $T^{\mathrm{STS}}, T^{\mathrm{OS}}$, and $T^{\mathrm{C}}$. The main target during Phase 2 is the 18-evaluation clouds for each subcriterion about each station. The data scale is quite large and, due to the limitation of the paper, we only present 6 stations' data as an example in Table 3. All the 6 stations will be retained as STS or OS after the site selection process.

During Phase 3, for each station, we use the weight in Table 3 to multiply the 18 subcriteria, respectively. After obtaining the final evaluation cloud for each station, we use MATLAB to plot the final evaluation cloud together with the evaluation clouds criteria $T^{\mathrm{STS}}, T^{\mathrm{OS}}$, and $T^{\mathrm{C}}$. The alternative for each station is presented in Table 4. As a result of the final evaluation in Wuhan Railway Bureau, only one station (Xiangyang) will be renovated and developed as a Special Transaction Station (STS) because its evaluation cloud (shown in Figure 5, the red cloud) is very close to the evaluation criteria clouds $T^{\mathrm{STS}}$ mentioned in Figure 3. Five stations will be kept and developed as Ordinary Stations (OS) and the remaining 16 stations will be closed (C). Also, we present some of the MATLAB visualization results in Figure 5; (a) is the sample about STS, (b) is the sample about OS, and (c) is the sample about C.

The layout of railway container stations in Wuhan Railway Bureau has changed significantly after the site reselection process. The calculation results show that before the site reselection process, the average distance between two railway container stations in Wuhan Railway Bureau was only $74.7 \mathrm{~km}$ but the distance has improved to $182.6 \mathrm{~km}$ after using 


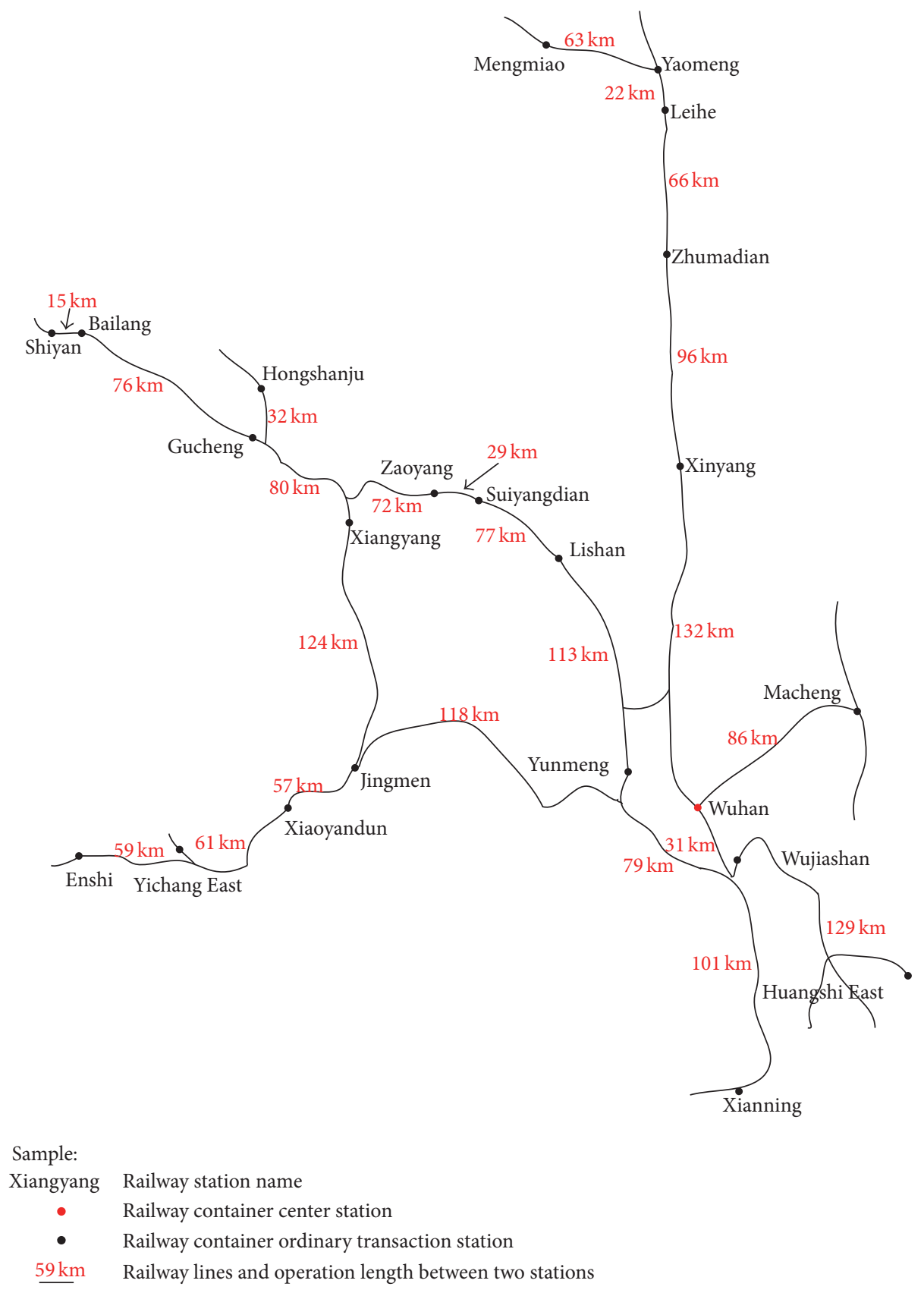

FIGURE 4: Layout of railway container transport network in Wuhan Railway Bureau.

the approach formulated in this paper. As a comparison, the layout of the remaining stations in Wuhan Railway Bureau is presented in Figure 6.

5.2. Initial Data and Calculation Results Based on AHP. AHP transforms a flexible multicriteria decision-making problem into a hierarchy with respect to one or more criteria, and it has been widely used for a variety of sites selection problem [2-14]. Next, we used the same case study for AHP as the calculation comparison with the formulated ECM proposed in this paper. The AHP determination steps are as follows: (i) for the 5 criteria as well as the subcriteria of each station under evaluation, the 10 experts compared each two of them with the importance coefficient from 1 to 9 and formed the initial judgment matrixes; the larger the value, the more important the criteria and (ii) calculated each of the judgment matrix and obtained the coefficients and then used the professional software yaahp v7.5 to obtain the final sequence for all the stations. The final sequences for all the stations are showed in Table 5.

XAY will be kept as a STS. ES, ZMD, HSE, JM, and YM will be kept as OS and the other stations will be closed. The final results are quite different from the results based on ECM which kept XN as an OS and not YM. Compared with the 


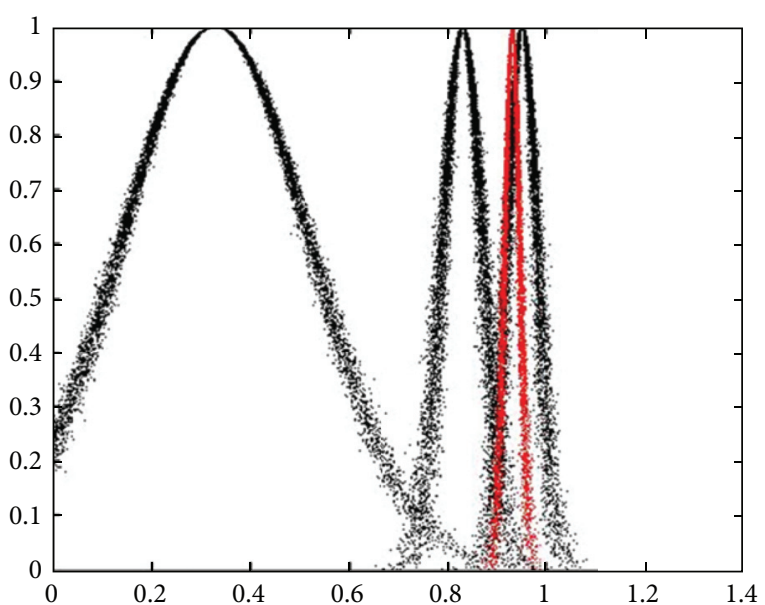

(a) $C_{\mathrm{XAY}}=G(0.93,0.015,0.003)$

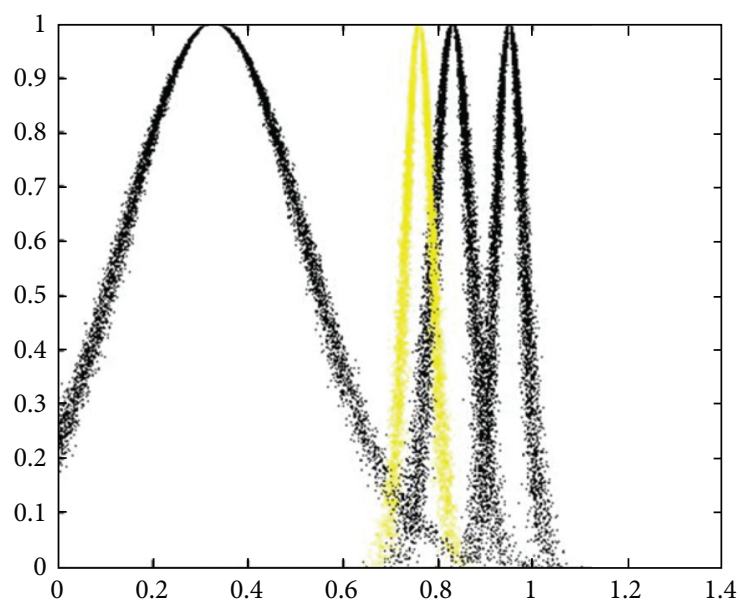

(b) $C_{\text {ZMD }}=G(0.76,0.028,0.005)$

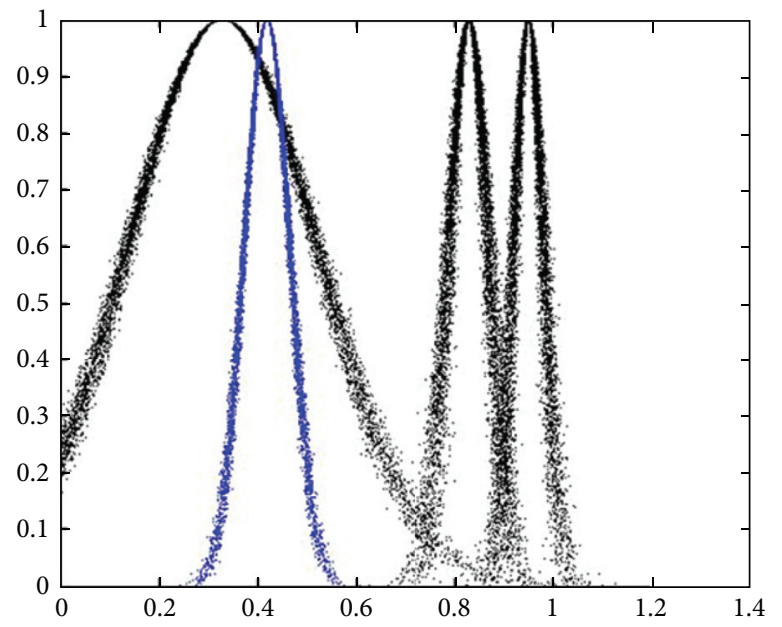

(c) $C_{\mathrm{MM}}=G(0.42,0.046,0.003)$

FIGURE 5: Visualization sample of STS (Xiangyang), OS (Zhumadian), and C (Mengmiao).

ECM, the AHP is easier to handle and the final sequence order is easy to obtain with the help of the professional software yaahp v7.5. But the disadvantages are also easy to find: (i) AHP method can only provide us with the order of the calculation results; we have to divide all the stations into three types, including STS, OS, and closed according to the sequence, artificially and (ii) when the final calculation value based on AHP is quite close, for example, the YM (0.0438) and $\mathrm{XN}(0.0437)$, it is hard to make the decision.

\section{Conclusion and Further Study Works}

According to China national strategic plan (2006-2010), 44 of the existing 520 railway container stations in China will be renovated and developed as STS, 100 stations will be kept and developed as OS, and the remaining 376 stations will be closed so the station evaluation and reselection process should be more objective and prudential. The whole process belongs to a SSP. The most commonly used method to solve the SSP is AHP both in theoretical research and in actual practice but the results are quite subjective and inaccurate. In this paper, we formulated an entropy-cloud approach to solve the railway container station reselection problem.

The ECM combines EM and CM and has three phases. During Phase 1, there are 18 subcriteria that need to be evaluated for each station; the EM is used to obtain the weight of each subcriteria objectively. Phase 2 is designed to form the evaluation cloud for each station based on CM. The ESM is applied to obtain the basic three evaluation criteria clouds and evaluation value for each subcriterion; then we calculate the Expectation Value, Entropy Value, and Super Entropy Value to obtain the initial station evaluation cloud for each subcriterion. Phase 3 is applied to obtain the final evaluation result for each station. To achieve the goal, we use the weight during Phase 1 to multiply the initial evaluation cloud for each subcriterion during Phase 2; then MATLAB is used to determine the four evaluation figures. We make our alternative according to the figures comparison and auxiliary determination formula. To test our approach proposed in this paper, the railway container stations in Wuhan Railway Bureau were selected for our case study. 22 stations are operating in Wuhan Railway Bureau now. The 

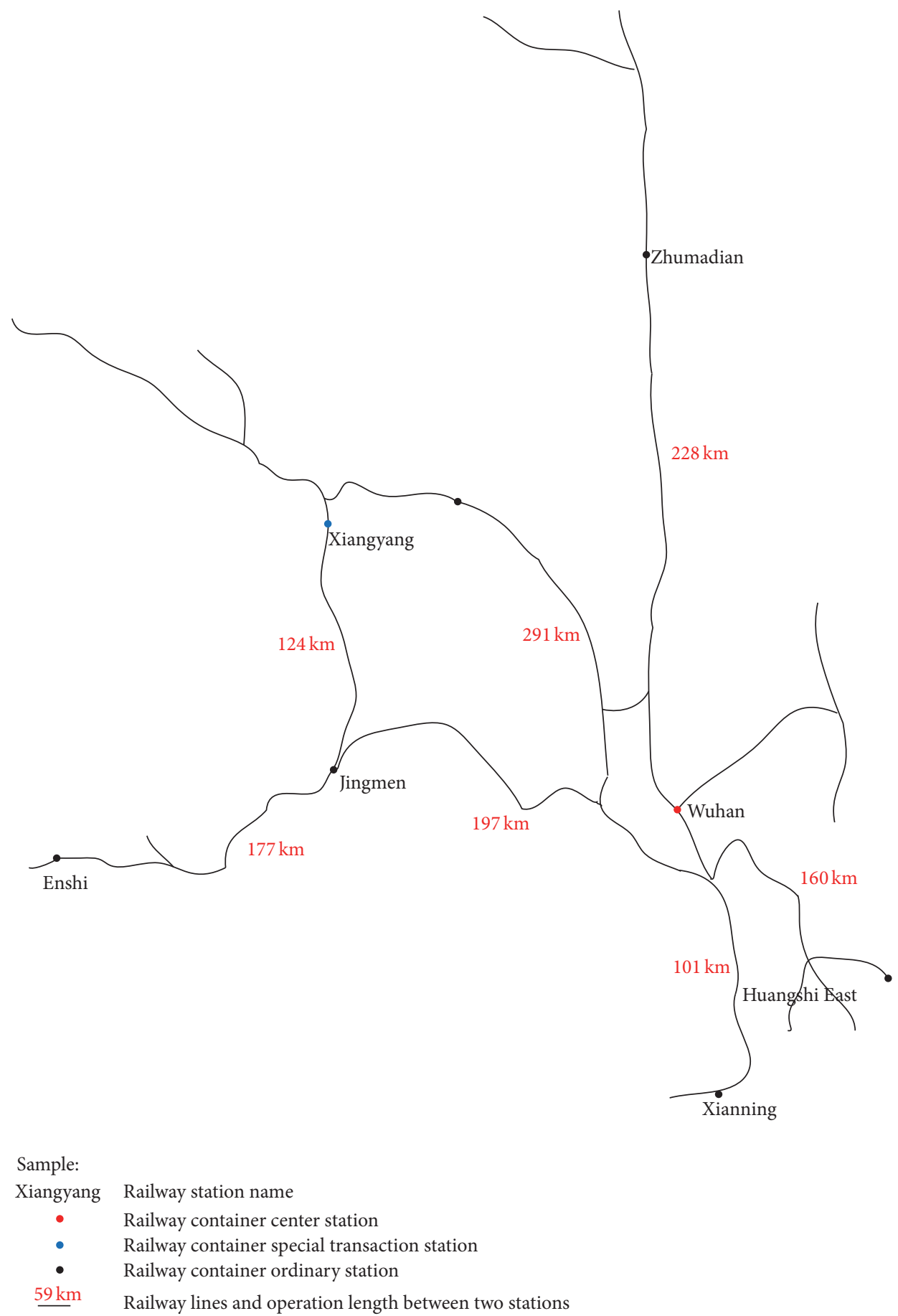

FIGURE 6: Layout of the remaining stations.

final evaluation results showed that only Xiangyang Station should be renovated and developed as a Special Transaction Station; Zhumadian Station, Jingmen Station, Enshi Station, Xianning Station, and Huangshi East Station should be kept and developed as Ordinary Stations and the remaining 16 stations should be closed. Furthermore, the results show that before the site reselection process the average distance between two railway container stations in Wuhan Railway
Bureau was only $74.7 \mathrm{~km}$, but it has improved to $182.6 \mathrm{~km}$ after using the approach formulated in this paper.

The approach which combines EM and CM was applied to solve the site selection problem. Compared with the most used AHP, the evaluation results are more objective and accurate. After the stations are classified, the container business/cargo in the closed stations must be transferred and coordinated to the other retained stations, so how to design 
TABLE 5: Final calculation sequence for all the stations based on AHP (in descending order).

\begin{tabular}{lc}
\hline Station & Calculation value \\
\hline XAY & 0.2983 \\
ES & 0.0541 \\
ZMD & 0.0522 \\
HSE & 0.0507 \\
JM & 0.0487 \\
YM & 0.0438 \\
XN & 0.0437 \\
XY & 0.0404 \\
LH & 0.0382 \\
BL & 0.0314 \\
SYD & 0.0311 \\
GC & 0.0298 \\
MM & 0.0287 \\
SY & 0.0286 \\
ZY & 0.0284 \\
MC & 0.0272 \\
YCE & 0.0268 \\
HSJ & 0.0267 \\
YM & 0.0199 \\
WSJ & 0.0189 \\
XYD & 0.0167 \\
LS & 0.0157 \\
\hline
\end{tabular}

and plan the transferring network as well as the coordinated approach is meaningful and necessary to study in the future.

\section{Competing Interests}

The authors declare that there are no competing interests regarding the publication of this paper.

\section{Acknowledgments}

This research was jointly supported by the Traffic and Transportation Engineering Experiment and Comprehensive Innovation Center, School of Transportation and Logistics, Southwest Jiaotong University, Chengdu, Sichuan and Subsidized by National Natural Science Foundation of China (71173177), China State Railway Administration of Science and Technology Legal Division (KF2013-020), and 2015 Graduate Innovative Experimental and Practice Program (YC201507103), Southwest Jiaotong University.

\section{References}

[1] L. Wang, "Development countermeasures research of railway container transportation," Railway Freight, vol. 1, pp. 51-53, 2013.

[2] A. Ballis, "Airport site selection based on multi-criteria analysis: the case study of the island of samothraki," Operational Research, vol. 3, no. 3, pp. 261-279, 2003.

[3] S. Önüt and S. Soner, "Transshipment site selection using the AHP and TOPSIS approaches under fuzzy environment," Waste Management, vol. 28, no. 9, pp. 1552-1559, 2008.
[4] J. L. Rosenberg and A.-M. Esnard, "Applying a hybrid scoring methodology to transit site selection," Journal of Urban Planning and Development, vol. 134, no. 4, pp. 180-186, 2008.

[5] M. Dağdeviren, S. Yavuz, and N. Kılınç, "Weapon selection using the AHP and TOPSIS methods under fuzzy environment," Expert Systems with Applications, vol. 36, no. 4, pp. 81438151, 2009.

[6] T. Kauko, "What makes a location attractive for the housing consumer? Preliminary findings from metropolitan Helsinki and Randstad Holland using the analytical hierarchy process," Journal of Housing and the Built Environment, vol. 21, no. 2, pp. 159-176, 2006.

[7] T. Kauko, "An analysis of housing location attributes in the inner city of Budapest, Hungary, using expert judgements," International Journal of Strategic Property Management, vol. 11, no. 4, pp. 209-225, 2007.

[8] Z. Srdjevic, V. Kolarov, and B. Srdjevic, "Finding the best location for pumping stations in the Galovica drainage area of Serbia: the AHP approach for sustainable development," Business Strategy and the Environment, vol. 16, no. 7, pp. 502-511, 2007.

[9] P. K. Dey and E. K. Ramcharan, "Analytic hierarchy process helps select site for limestone quarry expansion in Barbados," Journal of Environmental Management, vol. 88, no. 4, pp. 13841395,2008

[10] L. B. Liu, P. Berger, A. Zeng, and A. Gerstenfeld, "Applying the analytic hierarchy process to the offshore outsourcing location decision," Supply Chain Management, vol. 13, no. 6, pp. 435-449, 2008.

[11] J. L. García, A. Alvarado, J. Blanco, E. Jiménez, A. A. Maldonado, and G. Cortés, "Multi-attribute evaluation and selection of sites for agricultural product warehouses based on an analytic hierarchy process," Computers and Electronics in Agriculture, vol. 100, pp. 60-69, 2014.

[12] V. Padmaja, S. S. Asadi, and M. A. Reddy, "Integrated analytical hierarchy process-GIS model for landfill siting: a case study from India," in Proceedings of the 19th International Conference on Solid Waste Technology and Management, pp. 155-166, Philadelphia, Pa, USA, 2007.

[13] P. K. Dey, "An integrated assessment model for cross-country pipelines," Environmental Impact Assessment Review, vol. 22, no. 6, pp. 703-721, 2002.

[14] M. Timor and S. Sipahi, "Fast-food restaurant site selection factor evaluation by the Analytic Hierarchy Process," The Business Review, Cambridge, vol. 4, no. 1, pp. 161-167, 2005.

[15] J. Korpela, A. Lehmusvaara, and J. Nisonen, "Warehouse operator selection by combining AHP and DEA methodologies," International Journal of Production Economics, vol. 108, no. 1-2, pp. 135-142, 2007.

[16] H. Akinci, A. Y. Özalp, and B. Turgut, "Agricultural land use suitability analysis using GIS and AHP technique," Computers and Electronics in Agriculture, vol. 97, pp. 71-82, 2013.

[17] J. A. Carrión, A. E. Estrella, F. A. Dols, M. Z. Toro, M. Rodríguez, and A. R. Ridao, "Environmental decision-support systems for evaluating the carrying capacity of land areas: Optimal site selection for grid-connected photovoltaic power plants," Renewable and Sustainable Energy Reviews, vol. 12, no. 9, pp. 2358-2380, 2008.

[18] T. D. Kontos, D. P. Komilis, and C. P. Halvadakis, "Siting MSW landfills with a spatial multiple criteria analysis methodology," Waste Management, vol. 25, no. 8, pp. 818-832, 2005. 
[19] E. W. L. Cheng, H. Li, and L. Yu, "The analytic network process (ANP) approach to location selection: a shopping mall illustration," Construction Innovation: Information, Process, Management, vol. 5, no. 2, pp. 83-97, 2005.

[20] M. Banar, B. M. Kose, A. Ozkan, and I. P. Acar, "Choosing a municipal landfill site by analytic network process," Environmental Geology, vol. 52, no. 4, pp. 747-751, 2007.

[21] P. Aragonés-Beltrán, J. P. Pastor-Ferrando, F. García-García, and A. Pascual-Agulló, "An Analytic Network Process approach for siting a municipal solid waste plant in the Metropolitan Area of Valencia (Spain)," Journal of Environmental Management, vol. 91, no. 5, pp. 1071-1086, 2010.

[22] M. Ekmekçioĝlu, T. Kaya, and C. Kahraman, "Fuzzy multicriteria disposal method and site selection for municipal solid waste," Waste Management, vol. 30, no. 8-9, pp. 1729-1736, 2010.

[23] S. Önüt, T. Efendigil, and S. S. Kara, "A combined fuzzy MCDM approach for selecting shopping center site: an example from Istanbul, Turkey," Expert Systems with Applications, vol. 37, no. 3, pp. 1973-1980, 2010.

[24] J. J. Hoffman and M. J. Schniederjans, "A two-stage model for structuring global facility site selection decisions: the case of the brewing industry," International Journal of Operations and Production Management, vol. 14, no. 12-13, pp. 23-34, 1996.

[25] J. Brimberg and C. ReVelle, "A multi-facility location model with partial satisfaction of demand," Studies in Locational Analysis, no. 13, pp. 91-101, 1999.

[26] G. Schmidt and W. E. Wilhelm, "Strategic, tactical and operational decisions in multi-national logistics networks: a review and discussion of modelling issues," International Journal of Production Research, vol. 38, no. 7, pp. 1501-1523, 2000.

[27] M. Rönnqvist, S. Tragantalerngsak, and J. Holt, "Repeated matching heuristic for the single-source capacitated facility location problem," European Journal of Operational Research, vol. 116, no. 1, pp. 51-68, 1999.

[28] G.-S. Liang and M.-J. J. Wang, "Fuzzy multi-criteria decisionmaking method for facility site selection," International Journal of Production Research, vol. 29, no. 11, pp. 2313-2330, 1991.

[29] T. Semih and S. Seyhan, "A multi-criteria factor evaluation model for gas station site selection," Journal of Global Management, vol. 2, no. 1, pp. 12-21, 2011.

[30] F. Felice, A. Petrillo, and O. Cooper, "Multicriteria analysis to evaluate influence of green practices on supply chain performance," Science Journal of Business Management, vol. 2012, no. 2, pp. 1-12, 2012.

[31] I. Mahamid and S. Thawaba, "Multi-criteria and landfill site selection using GIS: a case study from Palestine," The Open Environmental Engineering Journal, vol. 3, no. 1, pp. 33-41, 2010.

[32] A. Mendas and A. Delali, "Integration of MultiCriteria Decision Analysis in GIS to develop land suitability for agriculture: application to durum wheat cultivation in the region of Mleta in Algeria," Computers and Electronics in Agriculture, vol. 83, pp. 117-126, 2012.

[33] M. Uyan, T. Cay, and O. Akcakaya, "A spatial decision support system design for land reallocation: a case study in Turkey," Computers and Electronics in Agriculture, vol. 98, pp. 8-16, 2013.

[34] D. Y. Li, H. J. Meng, and X. M. Shi, "Membership clouds and membership cloud generators," Journal of Computer Research and Development, vol. 32, no. 6, pp. 15-20, 1995.

[35] L. Li, L. Liu, C. Yang, and Z. Li, “The comprehensive evaluation of smart distribution grid based on cloud model," Energy Procedia, vol. 17, pp. 96-102, 2012.
[36] L. J. Fan, Y. X. Ling, L. C. Liao, and B. X. Li, "An improved evaluation method based on cloud models for situation consistency within the battlefield of joint operations," Procedia Engineering, vol. 29, pp. 1590-1595, 2012.

[37] L. Zhang, X. Wu, L. Ding, and M. J. Skibniewski, "A novel model for risk assessment of adjacent buildings in tunneling environments," Building and Environment, vol. 65, pp. 185-194, 2013.

[38] C.-B. Li, Z.-Q. Qi, and X. Feng, "A multi-risks group evaluation method for the informatization project under linguistic environment," Journal of Intelligent \& Fuzzy Systems, vol. 26, no. 3, pp. 1581-1592, 2014.

[39] L. Zhang, X. Wu, Q. Chen, M. J. Skibniewski, and J. Zhong, "Developing a cloud model based risk assessment methodology for tunnel-induced damage to existing pipelines," Stochastic Environmental Research and Risk Assessment, vol. 29, no. 2, pp. 513-526, 2015.

[40] Y. F. Ma and J. P. Xu, "A cloud theory-based particle swarm optimization for multiple decision maker vehicle routing problems with fuzzy random time windows," Engineering Optimization, vol. 47, no. 6, pp. 825-842, 2015.

[41] L. Wu, C. Zuo, and H. Zhang, "A cloud model based fruit fly optimization algorithm," Knowledge-Based Systems, vol. 89, pp. 603-617, 2015.

[42] W. H. Deng, G. Y. Wang, and X. R. Zhang, "A novel hybrid water quality time series prediction method based on cloud model and fuzzy forecasting," Chemometrics and Intelligent Laboratory Systems, vol. 149, pp. 39-49, 2015.

[43] X.-H. Wu, J.-Q. Wang, J.-J. Peng, and X.-H. Chen, "Crossentropy and prioritized aggregation operator with simplified neutrosophic sets and their application in multi-criteria decision-making problems," International Journal of Fuzzy Systems, vol. 18, no. 6, pp. 1104-1116, 2016.

[44] J. Wang, J. Wang, and H. Zhang, "A likelihood-based TODIM approach based on multi-hesitant fuzzy linguistic information for evaluation in logistics outsourcing," Computers \& Industrial Engineering, vol. 99, pp. 287-299, 2016.

[45] H. Zhang, P. Ji, J. Wang, and X. Chen, "A neutrosophic normal cloud and its application in decision-making," Cognitive Computation, vol. 8, no. 4, pp. 649-669, 2016.

[46] H. Zhang, R. Zhou, J. Wang, and X. Chen, "An FMCDM approach to purchasing decision-making based on cloud model and prospect theory in e-commerce," International Journal of Computational Intelligence Systems, vol. 9, no. 4, pp. 676-688, 2016.

[47] P. Liu and L. Shi, "The generalized hybrid weighted average operator based on interval neutrosophic hesitant set and its application to multiple attribute decision making," Neural Computing and Applications, vol. 26, no. 2, pp. 457-471, 2014.

[48] P. Liu, L. He, and X. Yu, "Generalized hybrid aggregation operators based on the 2-dimension uncertain linguistic information for multiple attribute group decision making," Group Decision and Negotiation, vol. 25, no. 1, pp. 103-126, 2016.

[49] J.-Q. Wang, L. Peng, H.-Y. Zhang, and X.-H. Chen, "Method of multi-criteria group decision-making based on cloud aggregation operators with linguistic information," Information Sciences, vol. 274, pp. 177-191, 2014.

[50] J.-Q. Wang, J.-J. Peng, H.-Y. Zhang, T. Liu, and X.-H. Chen, "An uncertain linguistic multi-criteria group decision-making method based on a cloud model," Group Decision and Negotiation, vol. 24, no. 1, pp. 171-192, 2015. 
[51] G. Wang, C. Xu, and D. Li, "Generic normal cloud model," Information Sciences. An International Journal, vol. 280, pp. 1$15,2014$.

[52] Y. Wu, K. Chen, B. Zeng, M. Yang, and S. Geng, "Cloud-based decision framework for waste-to-energy plant site selection-a case study from China," Waste Management, vol. 48, pp. 593603, 2016.

[53] L. Li, F. Fan, L. Ma, and Z. Tang, "Energy utilization evaluation of carbon performance in public projects by FAHP and cloud model," Sustainability, vol. 8, no. 7, article 630, 2016. 


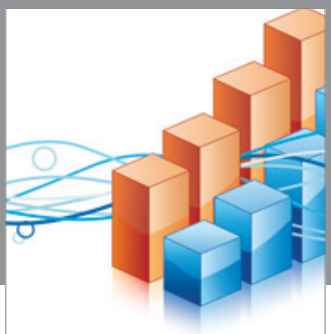

Advances in

Operations Research

vatem alat4

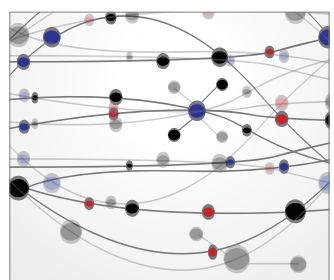

\section{The Scientific} World Journal
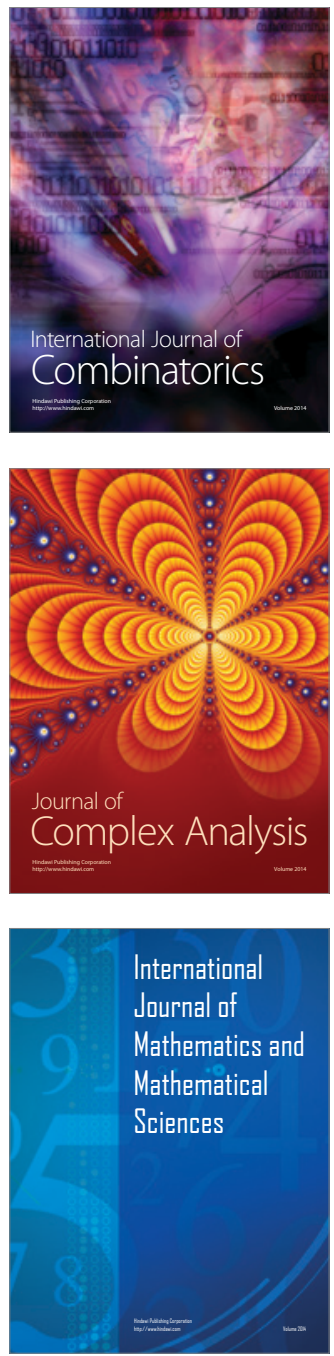
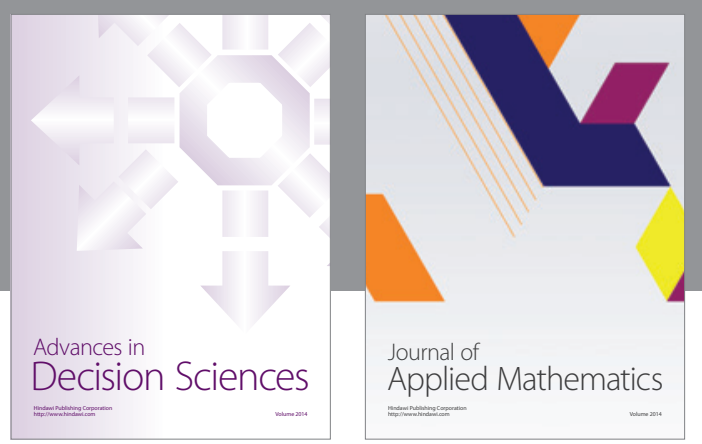

Algebra

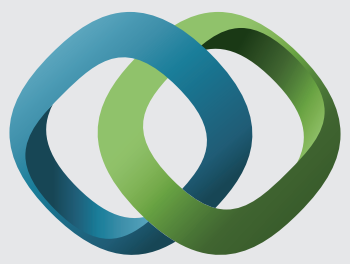

\section{Hindawi}

Submit your manuscripts at

https://www.hindawi.com
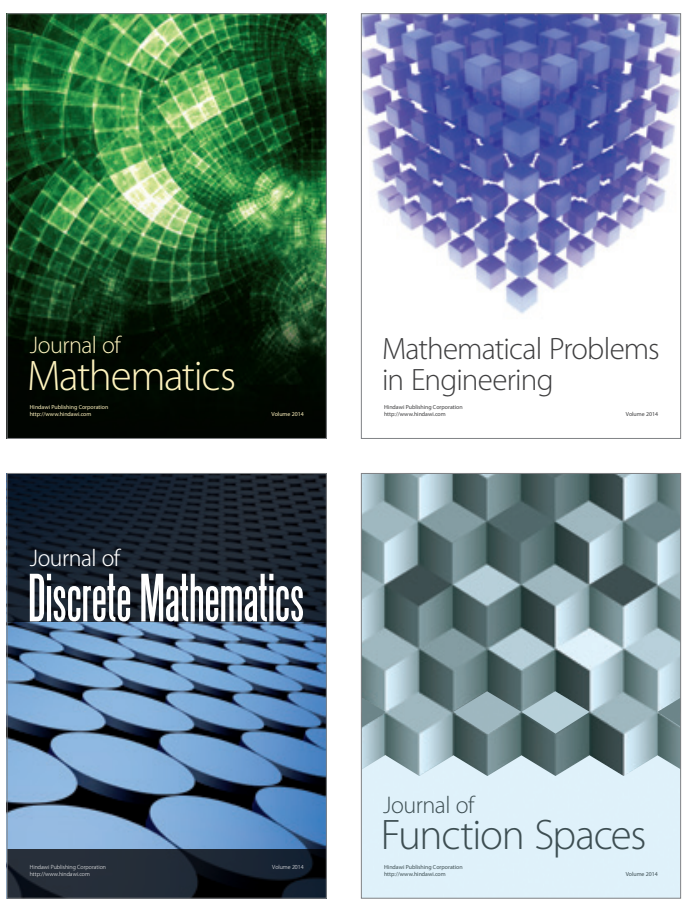

Mathematical Problems in Engineering
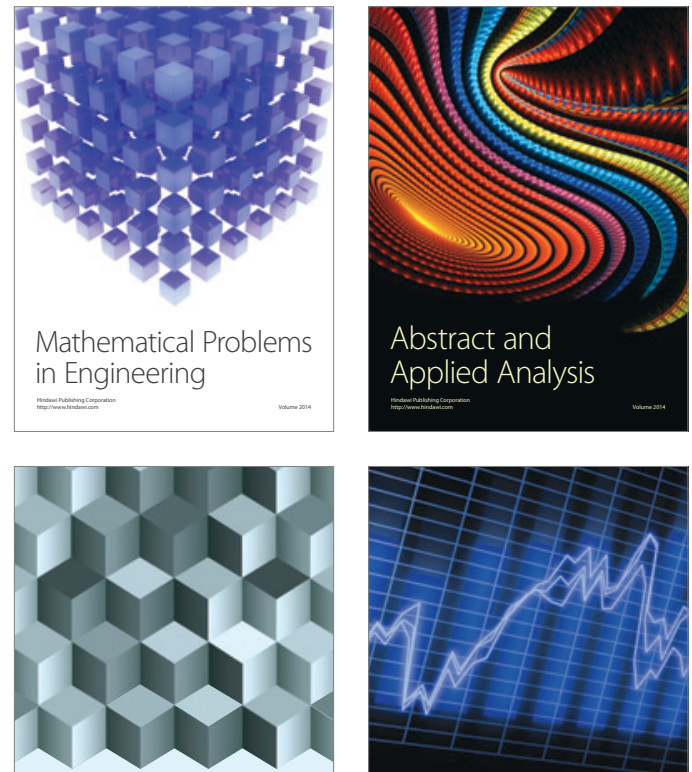

Journal of

Function Spaces

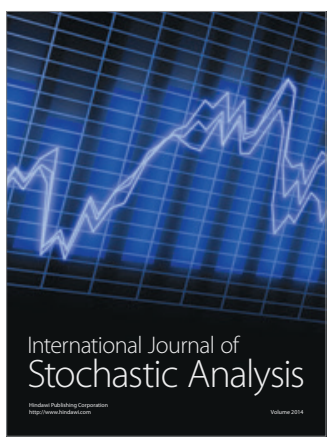

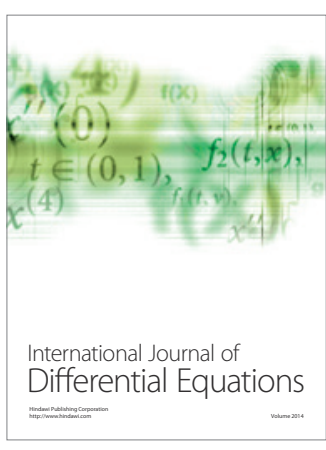
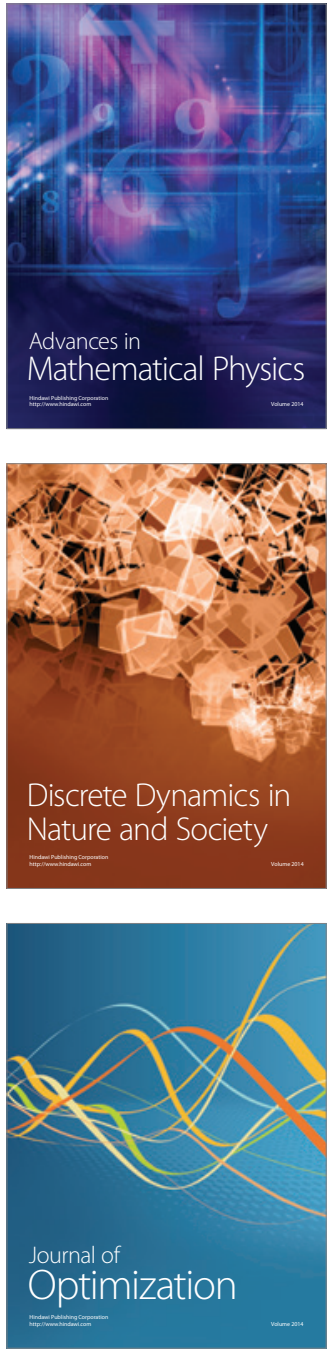